\title{
Big Data na Base de Dados Referencial de Artigos de Periódicos em Ciência da Informação (Brapci): um enfoque situacional
}

\author{
Big Data in the Reference Database of Journal Articles in Information Science (Brapci): a \\ situational approach
}

Lucileide Andrade de Lima do Nascimento Doutora em Ciência da Informação pela Universidade de Brasília - UnB, Brasil. Professora do Departamento de Biblioteconomia e Coordenadora Adjunta do Programa de Pós-Graduação Ciência da Informação da Universidade Federal do Espírito Santo - UFES, Brasil. https://orcid.org/0000-0001-8176-530 E-mail: lucileide.nascimento@ufes.br

Rosa da Penha Ferreira da Costa Doutora em Ciência da Informação pela Universidade de Brasília - UnB, Brasil. Professora do Departamento de Arquivolgia e Coordenadora do Programa de Pós-Graduação Ciência da Informação da Universidade Federal do Espírito Santo - UFES, Brasil. https://orcid.org/0000-0002-5379-1323

E-mail: rosa.costa@ufes.br

Marcelo Calderari Miguel
Professor e Especialista em Educação não Formal de Ciência e Tecnologia pela Universidade Federal do Espírito
Santo - UFES - Brasil.
https://orcid.org/0000-0002-7876-9392
E-mail: marcelo.miguel@edu.ufes.br

\section{Resumo}

Introdução: o gerenciamento de Big Data é considerado uma chave essencial no negócio de tecnologia e nessa via, o presente estudo evidencia a natureza interativa e a perspectiva bibliográfica sobre o tema Big Data, dando destaque ao cenário que situa múltiplos fenômenos informacionais contemporâneos. Objetivo: analisar a temática Big Data, no período de 2010 a 2019, em periódicos indexados na Base de Dados Referencial de Artigos de Periódicos em Ciência da Informação (Brapci). Metodologia: trata-se de uma pesquisa exploratória, quali-quantitativa que utiliza a pesquisa bibliográfica para levantamento de dados e indicadores bibliométricos da produção científica como forma de mapeamento. Identifica e quantifica a inserção da temática no campo científico brasileiro, representando graficamente as relações existentes. Resultado e Discussão: o diagnóstico levantou 152 artigos indexados, dos quais 118 se enquadram nos parâmetros estabelecidos no recorte amostral junto à base de dados Brapci. Assinala como principais veículos de publicação da temática os periódicos Ciência da Informação com nove artigos e Informação \& informação com oito artigos sobre o tema. Conclusão: o desenvolvimento do Big Data acompanha o ritmo da expansão dos dados socialmente produzidos e da tecnologia gerada na ambiência da web.

Palavras-chave: Big Data. Comunicação científica. Ciência da Informação. Bibliometria. Base de dados. Periódicos Científicos. 


\begin{abstract}
Introduction: Big Data management is considered an essential key in the technology business and in this way, this study highlights the interactive nature and bibliographical perspective on the Big Data theme, highlighting the scenario that situates multiple contemporary informational phenomena. Objective: to analyze the Big Data theme, from 2010 to 2019, in journals indexed in the Reference Database of Journal Articles in Information Science (Brapci). Methodology: this is an exploratory, quali-quantitative research that uses systematic bibliographic research to collect data and bibliometric indicators of scientific production as a form of mapping. It identifies and quantifies the insertion of the theme in the Brazilian scientific field, graphically representing the existing relationships. Result and Discussion: the diagnosis raised 152 indexed articles, of which 118 fit the parameters established in the sample cut along with the Brapci database. Its main vehicles for the publication of the theme are the journals Ciência da Informação with nine articles and Information \& information with eight articles on the subject. Conclusion: the development of Big Data keeps pace with the expansion of socially produced data and technology generated in the web environment.
\end{abstract}

Keywords: Big data. Scientific communication. Information Science. Bibliometrics. Data base. Scientific Journals.

\title{
1. Considerações iniciais
}

No âmbito das Ciências Humanas e Sociais Aplicadas, o termo Big Data vem gerando um rol de desafios, sendo possível delinear um perfazimento analítico da produção brasileira sobre o tema em três painéis, constando: i) levantamento de artigos publicados sobre Big Data em periódicos de Biblioteconomia (BIB) e Ciência da Informação (CI); ii) identificação de periódicos científicos com expressa representatividade na promoção dessa temática; e iii) circunscrição de pesquisadores em termos de titulação, instituições de origem e direcionamentos nos relacionamentos de coautorias. Por conseguinte, o estudo adentra em reflexões teóricas e práticas, e notadamente no âmbito acadêmico, lança lume em aspectos da interdisciplinaridade da CI como área de pesquisa, produzindo uma melhor compreensão sobre o conceito de Big Data. Salienta-se que a pesquisa bibliográfica realizada junto à Base de Dados Referencial de Artigos de Periódicos em Ciência da Informação (Brapci) privilegia aspectos da produção nacional, reconhecendo-se que a Brapci também indexa periódicos estrangeiros (SILVA; MIGUEL; COSTA, 2021).

Beloni e Bezerra (2019, p.2) esclarecem que o Big Data é considerado um fenômeno que responde pela produção de dados em velocidade tal que "[...] supera o desenvolvimento de ferramentas e métodos para gerenciá-los e analisá-los [...]". As autoras apontam para a multiplicidade de organizações, no ambiente web, trabalhando com os gigantes e volumosos dados produzidos gratuitamente por usuários nas redes e mídias sociais. 


\begin{abstract}
Nesse aspecto, há tanto questões éticas quanto questões legais que precisam ser atendidas, uma vez que é um dever para com os concedentes dos dados a transparência de como seus dados serão utilizados. Em muitos casos, essa informação sequer está disponível; em outros casos, quando os critérios de uso são informados, não é feito de forma compreensível ao sujeito que gerou os dados ou que recebe os dados, ou seja, a forma de manipulação desses dados não é apresentada com clareza [...] (BELONI; BEZERRA, 2019, p. 2).
\end{abstract}

Este estudo tem base em preceitos bibliométricos. Situa um painel que já foi abordado por vários autores que destacam esse campo temático: Costa e Cunha (2015) estudaram a literatura internacional sobre e-science nas bases de dados Library \& Information Science Abstracts (LISA) e Library, Information Science \& Technology Abstracts (LISTA); Fagundes, Macedo e Dutra (2017) observaram a qualidade de dados em Big Data na base de dados Web of Science; Peixoto e Barbosa (2017) buscaram na revisão de Literatura Sistemática um melhor entendimento das potencialidades e aplicações do Big Data Analytics (BDA) para criar inovação em produtos e processos; Fagundes, Macedo e Freund (2018) buscaram artigos nas bases de dados Scopus, Web of Science (WoS), LISA e Base de Dados Referenciais de Artigos de Periódicos em CI (BRAPCI); Lott e Cianconi (2018) analisaram o Big Data, consultando os Anais do Encontro Nacional de Pesquisa em Ciência da Informação (ENANCIB); e na mesma perspectiva adotada, o estudo de Santos-D'amorim, Cruz, Silva e Correia (2020) pautaram um levantamento bibliográfico como método de coleta dos artigos indexados na base Brapci.

Amoroso-Fernández e Costales-Ferrer (2016) citam que as oportunidades geradas pelo Big Data são enormes, mas também são desafiadoras no que tange à proteção de dados (privacidade, dados pessoais), à responsabilidade civil e aos direitos de propriedade intelectual dentre outros. Para os autores, uma das principais tarefas do governo é estruturar canais de relacionamento com a sociedade, ofertando de forma célere os canais, o acesso à publicação de políticas e leis para tornar o cidadão participante das decisões durante toda a tramitação do processo.

O termo 'Big Data' tem atilamento e desafios inúmeros e norteiam os campos profícuos da Biblioteconomia, Documentação, Computação, CI, Informática, Ciências Econômicas e Administrativas e o próprio domínio das Ciências de Dados, de forma diferenciada ou interrelacionada. A temática Big Data situa uma pauta constante em tais campos científicos acerca da velocidade, volume e variedade dos dados estruturados e não 
estruturados que são gerados diariamente. Incluindo-se também as questões de ordem ética, e assim, há que se destacar:

\begin{abstract}
No caso da história digital, o corolário das discussões sobre ética e big data é o de que as bases de dados não são neutras, sobretudo porque o processo de produção das informações históricas que compilamos foi atravessado por uma série de relações sociais no passado [...] Em termos epistemológicos, outro cuidado prende-se ao fato de que as inúmeras possibilidades de cruzamento de grandes volumes de informações tendem a deslocar o foco das pesquisas para a escala macroanalítica (RODRIGUES, 2020, p. 72).
\end{abstract}

Vanz, Santin e Pavão (2018) argumentam que o uso da bibliometria serve para a avaliação sistemática da pesquisa e tem por desígnio fundamentar as decisões estratégicas nas vias políticas da Ciência e Tecnologia $(\mathrm{C} \& \mathrm{~T})$ - isto é, na prática, esses autores demonstram o que é comum em vários países, e salientam que a bibliometria vem se tornando uma prática institucionalizada. Deste modo, convém enfatizar que diagnósticos bibliométricos vêm se consolidando como uma 'ferramenta de gestão' da pesquisa e um instrumento que subsidia a tomada de decisão - direcionando as políticas científicas, a alocação de recursos, o estabelecimento de prioridades, a identificação e o reconhecimento dos agentes mais adequados ao acaudilhar da coletividade.

Silva, Hayashi e Hayashi (2011, p. 126) apontam, contudo, que a presença dos profissionais da área da CI na realização de análises bibliométricas ainda é “[...] tímida quando comparada com a de especialistas de outras áreas de conhecimento".

Santos e Ferreira (2017, p. 1) entendem que os métodos bibliométricos servem para “[...] comprovar a eficácia das pesquisas estatisticamente, e isso tem se tornado cada vez mais frequente". Desta forma, se percebe que os indicadores bibliométricos cooperam largamente para apreender conteúdos constitutivos e particulares ao vocábulo Big Data - o qual adquire substanciosas interações entre as ciências da computação, comunicação, documentação e administração.

Assim, o diagnóstico situa os dados de forma agrupada e direciona-se pelos preceitos da abordagem bibliométrica. Sabe-se que a bibliometria baliza indicadores métricos importantes que servem para averiguar o caminhar (por vias quantitativas e a questão da variabilidade denotam e viabilizam algo a ser constatado) da produção técnica e científica. Nesse painel, entende-se que a Biblioteconomia e a CI abarcam um rol das "[...] áreas cientificas que se preocupam com a cultura da tecnologia" e com potencial para “[...] não só 
colaborar com esses estudos, como trazer colaborações interdisciplinares e ainda dar maior visibilidade para a área da CI" (LINS, 2015, p. 90). Na próxima seção tratamos de aspectos teóricos e pragmáticos do Big Data nos âmbitos da produção brasileira em Biblioteconomia e CI.

\section{Teoria e explanações em Big Data}

O termo Big Data pode ser entendido não apenas como um conceito abstrato criado pelo universo da tecnologia da informação, mas também expressão de uma forte tendência da pulsante atividade digital (OHL, 2014). Contudo, o termo se tornou "[...] banal, visando a descrever quaisquer amontoados de dados que não possam ser processados sem que se tenha à disposição estruturas de computação específicas [...]” conforme expõem Souza, Almeida e Porto (2013, p. 167).

A partir da ótica da CI e do contexto tecnológico, Barbosa e Kobashi (2017, p. 116) assinalam que as estruturas do Big Data vêm sendo pautadas a partir de dois esquemas de visualização de dados, isto é: i) um painel de extroversão que "[...] tem o enfoque no objeto exterior, nos fatos e pessoas em que se observa a atenção para a ação, comunicabilidade, sociabilidade e facilidade de expressão [...]" e; ii) um painel de introversão que possui um “[...] enfoque no objeto interior, na ação reflexiva, reservada. Para os pesquisadores, o Big Data situa um contexto e campo de atuação centrado na "[...] capacidade exponencial de produção, armazenamento e processamento de grandes volumes de dados e informações" (BARBOSA; KOBASHI, 2017, p. 117).

Por mais que Big Data seja um tema recente na produção científica seu cerne remete a meados da década de 1940, conforme afirmam Bufrem, Silva, Sobral e Correia (2016), e tal período situa grandes discussões imbricadas pelo período subsequente à segunda guerra mundial. A partir de 2014 os estudos internacionais pautados no Big Data "[...] despontaram de forma expressiva, sabe-se que o conceito referente ao mencionado termo é convergente à tecnologia de grid computing, sendo o Big Data um estágio que envolve processamento/descobertas a partir de dados advindos [...] do grid computing" (BUFREM et al. 2016, p. 52). Conceição (2017) instiga que o Big Data remete na prática à necessidade do usuário e no mais aponta que vem sendo considerado como: 
[...] a revolução da coleta de dados na rede. É capaz de gerar, processar e armazenar dados de um indivíduo de maneira rápida, em grande quantidade e disponível digitalmente. Aqui os dados são coletados para tomadas de decisão, [...]. O Big Data é como um sistema de backup capaz de guardar tudo [...]. A função inicial do Big Data era traçar e estabelecer padrões de usuários na web, por onde navega, por que e o que lhe interessa [...] (CONCEIÇÃO, 2017, p. 37-41).

Araújo Júnior e Sousa (2016) consideram que o Big Data aporta vasto atacado de dados, estruturados ou não, orientados ao processo decisório permitindo condição de análise e avaliação com alta precisão para tomada de decisão orientada ao desenvolvimento de corporações. Para esses pesquisadores, o Big Data possui cinco pressupostos básicos que permitem a modelagem dimensional de dados e sua posterior recuperação, e isto envolve cinco dimensões: volume - velocidade - variedade - veracidade - e valor. O 'valor' é o que de fato "[...] reveste a informação de uma importância estratégica como subsídio ao processo de tomada de decisão." Neste sentido, o ecossistema de Big Data pode ser caracterizado como um "[...] provedor de informações com valor agregado mensurável e de rastreabilidade que acrescentam relevância aos conjuntos de dados" (ARAÚJO JÚNIOR; SOUSA, 2016, p. 190).

Rautenberg e Carmo (2019) aludem que o conceito de Big Data expressa o processamento de dados heterogêneos, volumosos, dinâmicos e complexos que demandam, por decorrência, soluções de computação não tradicionais. Big Data relaciona-se basicamente à infraestrutura de hardware e de serviços computação nas nuvens. A complexidade crescente de processamento vem produzindo a sua evolução do padrão 3Vs para os modelos 6Vs no que se refere à características essenciais dos dados.

Em outras palavras, considerando a evolução dados $\rightarrow$ informação $\rightarrow$ conhecimento, o conceito Big Data é relacionado à camada basilar de materiais, privilegiando os 6Vs atribuídos aos dados (Velocidade, Variedade, Variabilidade, Veracidade, Volume e Valor). Neste sentido, advoga-se que a Ciência da Informação tem papel fundamental na consolidação dos ecossistemas de Big Data (RAUTENBERG; CARMO, 2019, p. 63).

Coneglian et al. (2018, p. 139) argumentam que a "[...] migração do analógico para o digital pode ser apontada como uma das principais responsáveis pela imersão deste cenário de Big Data”. A dinâmica de sucesso para a tomada de decisão está diretamente interligada ao momento e a rapidez que tal decisão é tomada, e assim os pesquisadores enfatizam que a variedade dos dados (estruturados, semiestruturados e não estruturados) sinaliza um construto desafiador e exige estruturas computacionais com mais flexibilidade e adaptabilidade para extrair o valor de representações tão distintas, conforme pesquisas de Sangeetha e Prakash (2017) e Oussous et al. (2018). 
Destarte, ao resgatar os tempos hodiernos e a conjectura que envolve o Moderno Profissional da Informação (MPI), entende-se que: como consequência dessa evolução, tanto as instituições quanto a academia estão conformando um novo olhar na condução de análises de dados devido ao fenômeno Big Data. Essa nova forma de análises está sendo chamada de Big Data Analytics; e, possibilita “a identificação de padrões e comportamentos que até então estavam imperceptíveis para as análises realizadas integralmente por humanos, ou com o auxílio de máquinas mais rudimentares, quando comparadas com as utilizadas atualmente" (CONEGLIAN; GONÇALVEZ; SEGUNDO, 2017, p. 141).

Cabe destacar que o termo Big Data é "[...] abordado na literatura sobre diferentes perspectivas e não há um conceito único em relação a ele, porém a ideia principal pode ser definida como sendo ambientes que envolvam o uso de grandes quantidades de dados para a tomada de decisões de forma mais precisa" (FREUND; FAGUNDES; MACEDO; DUTRA, 2019, p. 138). De maneira geral, esclarecem os pesquisadores, há sete requisitos que caracterizam Big Data: Legalidade, Privacidade, Inconsistência, Incompletude, Ambiguidade, Latência, Confiabilidade, Veracidade e Modelos de Aproximação.

O mercado de Big Data tem se expandido em compasso similar ao crescimento do volume de dados, com taxas anuais de crescimento da ordem de $26.24 \%$ constituindo um mercado que movimenta mais de 41 bilhões de dólares, conforme dados apontados pelo International Data Corporation (IDC) recentemente (REIS; SÁ, 2020). Desta forma, os pesquisadores perspectivam no âmbito da análise da temática Big Data - um campo novo e próspero e - com potencial para provocar um real fascínio nos modernos profissionais da informação (MPI) e diversos interagentes de áreas afins. Assim é pertinente destacar que lidamos com um alto padrão de inovação tecnológica produzida pela conjuntura contemporânea e com aplicações bem caracterizadas em contextos de organizações públicas e privadas. Por isso, considera-se fundamental o alerta relativo ao inter-relacionamento entre os
três paradoxos do big data: a transparência, a identidade e o poder. A razão da
preocupação guarda relação com o caráter mais invasivo que proporciona o big data:
não havendo transparência de onde, quando e como os dados são coletados, não
haveria condições do titular do dado pessoal consentir com o tratamento e a
correspondente utilização das informações (SZINVELSKI; ARCENO;
FRANCISCO, 2019, p. 142).

Rodrigues, Duarte e Dias (2017) assinalam que existem muitas outras preocupações, controvérsias e tensões a serem ponderadas no âmbito da gestão de dados via Big Data. Citam 
as questões relativas ao perfil de profissional adequado ao gerenciamento desse padrão de dados, um perfil ainda em construção que sinaliza para múltiplas competências e aptidões em diversos outros domínios, além do tecnológico.

A ausência de consenso na literatura para a conceituação do Big Data e a condição de uma área de estudos em plena ascensão condiciona, em certa medida, o pesquisador a mobilizar-se para integrar definições anteriores, como também a adjacência da temática, em geral, designa de modo genérico e indistinto o relevo dos 6Vs (Volume, Variedade, Velocidade, Valor, Veracidade, Variabilidade). O ponto geral às definições é que o Big Data apresenta a capacidade de relacionar dados e isso, para Reis e Sá (2020, p. 247) expressa a direção, no âmbito do mercado, para que "[...] a empresa obtenha vantagem competitiva ao traduzir o resultado da análise de dados em ajustes na tomada de decisões, criação de novos produtos e adaptação das estratégias em tempo real".

Em alta os ambientes dinâmicos de informação são expressão da potencialidade de gerar negócios e, impulsionar as empresas e o próprio mercado a usarem com eficiência grandes volumes de dados, considerando tanto os recursos quanto às capacidades que o processamento via Big Data oferece (volume, variedade, velocidade e valor, veracidade e variabilidade). A visão baseada em recursos na ofensiva tecnológica sinaliza que o Big Data cria a vantagem competitiva. Portanto, os campos de ação do Big Data são vastos, abrangendo segmentos novos e de ligeiro crescimento de dados como mídia e entretenimento, saúde e vigilância. No campo de lazer e negócios das redes sociais, por exemplo, o Big Data, adentra um rol de recursos de captação de dados e constitui diferentes relações com distintos graus de prospecção do Facebook, Foursquare e Twitter - novas fontes de dados nas quais os consumidores fornecem fluxos de dados quase contínuos sobre si mesmos.

Portanto, falar de Big Data é assumir que tudo, ou quase tudo, pode ser mensurável e quantificável, isso significa que através do Big Data, a psicopolítica digital aponta para o fim da pessoa e do livre-arbítrio, visto que cada “[...] dispositivo, cada técnica de dominação, produz seus próprios objetos de devoção, que são empregados para a submissão, materializando e estabilizando a dominação" (HAN, 2018, p. 24). Para o autor, o Big Data tem a capacidade de reunir uma quantidade imensa de dados (acumulação contínua de informações) e de registrar tudo (adição de informações), e assim pode “[...] promover 
padrões coletivos de comportamento dos quais não seríamos conscientes como indivíduos". (HAN, 2018, p.89).

No debate, ainda inconcluso, há a questão da prática em Big Data para gerenciamento de recursos humanos (chamada de People Analytics) que para Francisco, Silva e Martinez (2019, p. 224) expressa um procedimento de levantamento e exame de "[...] um grande volume de dados dos trabalhadores de uma organização com a finalidade de se estabelecer um diagnóstico e oferecer previsões que possam subsidiar o processo decisório relacionado à gestão de pessoas" - isto é gerir pessoas de forma estratégica e escorada em utilitários dados, o que resulta para a organização e para os trabalhadores em diversos benefícios, mas também em múltiplos e altos riscos.

Convém destacar que o tópico analisado é amplo e há um rol de diferentes olhares quanto à natureza e expansão de grandes dados, conforme aponta os estudos de Ramos (2015) e Conceição (2017). Destarte, o objetivo da investigação é analisar a aparição do tema Big Data nos periódicos de Biblioteconomia (BIB) e Ciência da Informação (CI) no Brasil. Com essa pesquisa pretende-se conhecer o histórico de alguns periódicos científicos que destacam o tema Big Data demonstrando os períodos em que o tópico aparece na literatura cientifica e em qual contexto esse assunto se torna mais publicizado.

\section{Procedimentos metodológicos}

Este trabalho, de caráter exploratório, utiliza metodologia própria à pesquisa do tipo bibliográfica, e analisa quais são as revistas na base Brapci que publicaram o tema Big Data nos últimos dez anos (2010-2019). A abordagem está embasada em indicadores bibliométricos e, tal tipo de análise, tem um papel e perspectiva relevante para se descobrir o encaminhamento da produção científica. Além disso, considera-se que indicadores bibliométricos contribuem amplamente para entender e pautar novos estudos acerca do Big Data na ciência, tecnologia e recriação (seja artística, histórica, cinematográfica e antropológica, dentre outras).

A atividade de pesquisa constituída segue uma abordagem mista (quantitativa e qualitativa) ao coletar e interpretar os dados. O estudo emprega os preceitos da revisão bibliográfica - ou seja, delineia com partes análogas reunidas, sob um aporte estatístico, 
atributos essenciais de itens documentais relevantes a discussão de assunto núcleo. Nessa medida, a seleção da Brapci se adéqua para indicar um rol de materiais referentes ao tema conforme assinalam a pesquisa de Silva, Miguel e Costa (2021).

Santos-D'amorim et al. (2020, p. 19) apontam que “[...] a temática Big Data é convergente e de interesse a várias outras áreas de conhecimento, sobretudo no cenário em que a informação é protagonista, logo, saber tratá-la e utilizá-la implica dirimir problemas".

Por conseguinte, o estabelecer de um diagnóstico adentra numa dimensão exploratória da pesquisa; e o nortear da problemática é explanar a produção cientifica envolvendo o 'Big Data'. Em suma, a análise exploratória demarca um locus (base de dados Brapci) para coleta de um rol de periódicos indexados e pertinentes às áreas científicas da BIB e da CI, mas que serão analisados de acordo com aproximações que serão construídas à medida da análise, podendo variar de acordo com a natureza dos dados levantados.

A Brapci indexa periódicos (nacionais e internacionais) e alguns anais de congressos das áreas BIB e CI, em síntese, facilita a consulta e o acesso direto a mais de 60 revistas científicas. Para Bufrem et al. (2016) a Brapci amplia o espaço documentário facilitando a visão de conjunto da produção de pesquisadores e nações, e ao mesmo tempo revela especificidades atinentes a um domínio científico.

Portanto, ao dar uma percepção de valor aos dados resgatados, obtêm-se uma medida para a produção científica (autores, periódicos, lugar, rede de cooperação, instituições envolvidas e outros quantitativos diversos) - isso é a essência da análise bibliométrica. Tal construto reporta Vanz, Santin e Pavão (2018, p. 8), se expandiu em “[...] várias áreas, especialmente na CI e consolidou-se fortemente a partir de 1979, com a publicação do periódico internacional Scientometrics".

Dessa forma, o levantamento bibliográfico realizado na Brapci no dia oito de julho de 2020 propiciou a organização dos dados coletados em planilhas eletrônicas (software Excel da Microsoft) visando tabular, filtrar, contar, sintetizar e representar graficamente os dados recuperados. Os critérios de pesquisa previamente definidos situaram a estratégia de recuperação de itens documentais indexados na Brapci. O critério principal identificou o termo de busca 'Big Data' no rol de autores, título, palavras-chave, resumo, texto completo 
(todos os campos) e foi refinado a partir de delimitação temporal de dez anos, considerando o período de 2010 a 2019.

Os itens documentais atinentes à temática proposta estão divididos por: i) marco temporal; ii) periódicos que mais acolhem o tema; e iii) pesquisadores mais produtivos. A partir dessa categorização, examinou-se textos recuperados caracterizando a abrangência, evolução e difusão de pesquisas e estudos acadêmico-científicos que acolhem no título, palavras-chave ou resumo a apreciação do tema Big Data.

\section{Resultados e Discussões}

Esse estudo modera uma apreensão a partir de pesquisa bibliográfica sobre o tema Big Data, utilizando busca e captura avançada de itens documentais na Base de Dados Brapci. No total constituiu-se um somatório de 152 itens documentais revocados entre o período de 2010 a 2019. Após a análise de pertinência do conteúdo recuperado (identificando-se irregularidades e repetições) restou um conjunto de 118 indicações documentais válidas ao estudo da temática conforme representado na Tabela 1. A análise da busca por meio do termo Big Data e das subcomposições de buscas resultaram no seguinte painel: Big Data (93 itens documentais recuperados), Grandes Dados (56 itens) e Mega dados (3 indicações).

Tabela 1 - O situar de dados da pesquisa.

\begin{tabular}{c|c|c|c|c}
\hline Documentos localizados na durante processo de busca junto à Brapci & $152=$ itens documentais \\
\hline Fases & \multicolumn{3}{|c|}{ Eliminação de itens } & \multicolumn{2}{c}{ Itens remanescentes } \\
\hline $1^{\text {a } \text { etapa - crivo temporal }}$ & 14 & $\mid$ Duplicados & 138 & $90,79 \%$ \\
\hline $2^{\text {a }}$ etapa - a via pertinência & 10 & $\mid$ Fora do foco| & 128 & $84,21 \%$ \\
\hline $\begin{array}{c}3^{\text {a }} \text { etapa - crivo tipológico } \\
\text { subconjuntos }\end{array}$ & 10 & $\begin{array}{c}\mid \text { Entrevistas | Editorial| } \\
\text { TCC }\end{array}$ & 118 & $77,63 \%$ \\
\hline
\end{tabular}

Fonte: elaboração própria. Nota: produzido durante a pesquisa. Busca por campos (palavras-chave, referências, resumo, título) e refinado com asterisco.

De modo geral e histórico, foram recuperados na Base de Dados Brapci e considerados como amostra válida 118 itens documentais (considerando o período de cobertura de 2010 a 2019) e que compõem corpus literário sobre o tema Big Data. Nessa via, com o recorte temporal, a questão de impertinência ao tema, e o crivo tipológico de abordagem se estabelece 
em um conjunto de artigos de periódicos oriundos de relatórios científicos no rol de representatividade desse estudo.

\subsection{Marco temporal e produtivo}

O levantamento de artigos publicados sobre o termo Big Data em periódicos indexados na Base de Dados Brapci, caracterizado como pesquisa bibliométrica, foi sinalizada com o uso do asterisco (*), caráter-curinga, e do termo de busca assinalado com 'todos' nos campos de pesquisa. Foram recuperados itens que exibem pontos de especificidade relativos à temática acolhida em torno do crescimento anual da produção científica.

Gráfico 1 - Recorte da produção acadêmico-científica sobre Big Data (2010-2019).

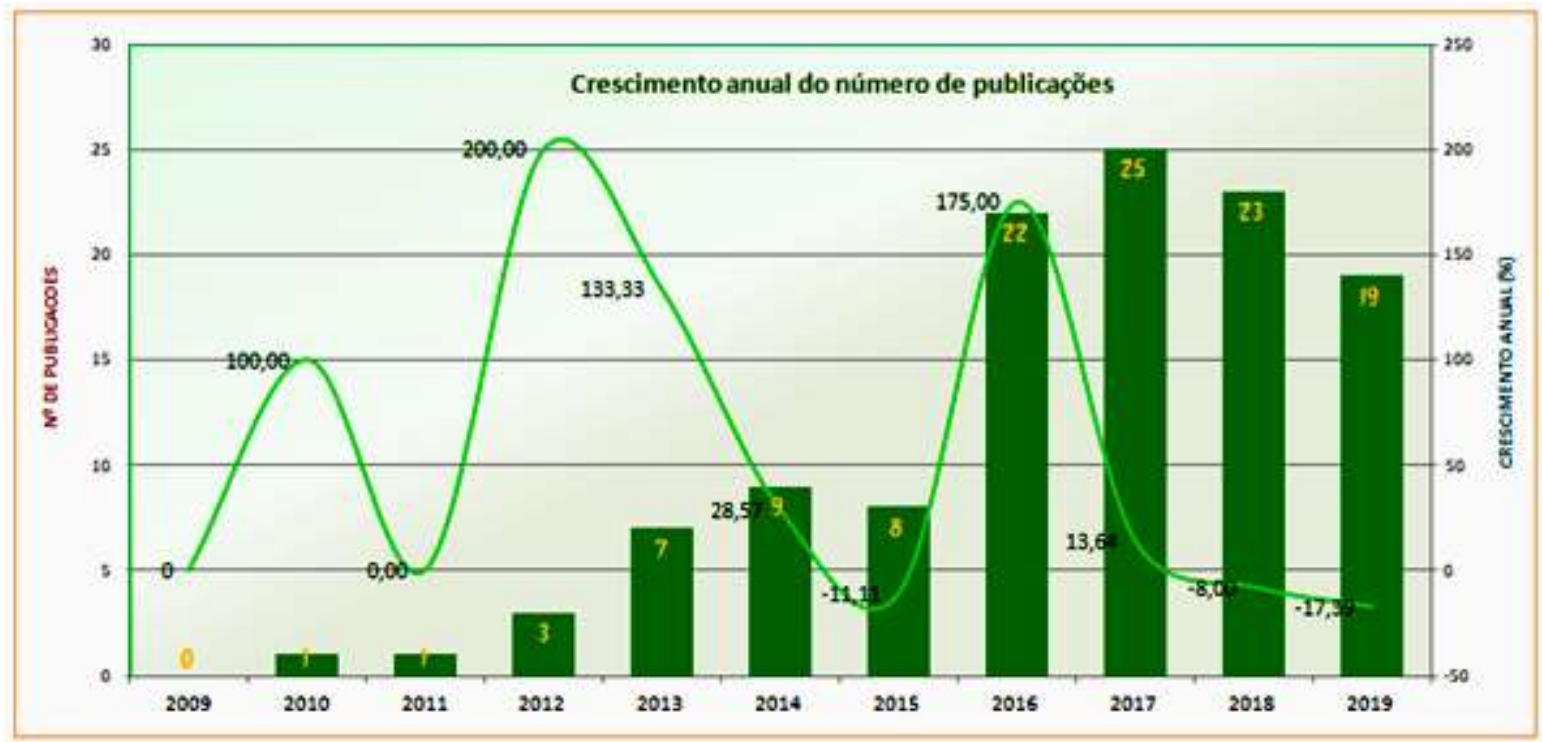

Fonte: elaboração própria.

Nota: produzido durante a pesquisa com base nos dados levantados na Brapci.

Conforme representado no Gráfico 1 a temática vem obtendo avanço e, dessa forma, ao observar-se o lapso temporal de 2016 a 2019 identifica-se que o tema Big Data obteve considerável expansão na literatura científica. Tal metáfora visual, como mencionam Martínez-Martíne e Lara-Navarra (2014) permite uma reflexão mais ampla destacando que o impacto do Big Data na infoera é medido em termos quantitativos e qualitativos.

Observou-se também na área de CI oito grupos de pesquisa certificados tratando da temática Big Data: Ciência, Dados, Redes e Metrias e o grupo Gestão do Conhecimento e Prospecção em Saúde (Scimetrics), ambos da Fundação Oswaldo Cruz (Fiocruz); Estudos e 
Práticas de Preservação Digital (IBICT) do Instituto Brasileiro de Informação em Ciência e Tecnologia; Representação do Conhecimento, Ontologias e Linguagem da Universidade Federal de Minas Gerais (UFMG); Inteligência, Tecnologia e Informação - Research Group (ITI-RG) da Universidade Federal de Santa Catarina (UFSC); Memória Social, Tecnologia e Informação da Universidade Federal do Estado do Rio de Janeiro (UNIRIO); Núcleo de Estudos em Web Semântica e Análise de Dados (NEWSDA) e o Observatório do Mercado de Trabalho em Informação na Era Digital, ambos da Universidade de São Paulo USP). Porém, nesta pesquisa, serão trabalhados apenas os periódicos e autores que mais produziram sobre o tema, como explanado a seguir.

\subsection{Periódicos na acolhida de um tema}

Recorrendo-se à Base de Dados Brapci foram recuperados e identificados 118 artigos publicados, em 36 revistas/eventos distintos, dando enfoque especial à questão dos Grandes Dados ou Big Data. Os periódicos classificados no Qualis Capes Periódicos da área de Comunicação e Informação com maior representatividade (Qualis A1 e A2), considerando o quadriênio 2013-2016, na publicação sobre o tema Big Data são: Informação \& Sociedade com seis publicações e a revista Informação \& Informação com oito artigos no período de 2010 a 2019. Contudo a maior concentração de publicações sobre o tema se encontra no extrato B1 com $44(37,29 \%)$ da totalidade dos artigos publicados, e isto é condizente com o quantitativo (numérico representativo) de periódicos que se situam nessa classificação. As principais revistas e a quantidade de publicações localizadas no âmbito da Brapci com tema em pauta é representado a seguir - conforme a classificação no Qualis Capes da área de Comunicação e Informação (quadriênio 2013-2016). A Tabela 2 representa os títulos de periódicos e a quantidade de respectivos itens documentais. 
Tabela 2 - Periódicos e eventos* que publicaram sobre o assunto Big Data entre 2010 a 2019.

\begin{tabular}{|c|c|c|c|c|}
\hline PERIÓDICOS & $\begin{array}{c}\text { Estrato } \\
\text { Qualis }\end{array}$ & $\begin{array}{c}\text { Quant. de } \\
\text { artigos }\end{array}$ & Acum. & Perc. \% \\
\hline Informação \& Sociedade: Estudos & A1 & 6 & \multirow{3}{*}{13} & \multirow{6}{*}{$23,73 \%$} \\
\hline Perspectivas em Ciência da Informação & A1 & 6 & & \\
\hline Biblios (Peru) & $\mathrm{A} 1$ & 1 & & \\
\hline Informação \& Informação & $\mathrm{A} 2$ & 8 & \multirow{3}{*}{15} & \\
\hline Encontros Bibli & $\mathrm{A} 2$ & 5 & & \\
\hline Em Questão & $\mathrm{A} 2$ & 2 & & \\
\hline Ciência Da Informação & B1 & 9 & \multirow{11}{*}{44} & \multirow{11}{*}{$37,29 \%$} \\
\hline Liinc Em Revista & B1 & 7 & & \\
\hline Brazilian Journal of Information Science & B1 & 5 & & \\
\hline Tendências da Pesquisa Brasileira dm Ciência da Informação & B1 & 5 & & \\
\hline Ciencias de la Información (Cuba) & B1 & 3 & & \\
\hline Pesquisa Brasileira em Ciência da Informação e & B1 & 3 & & \\
\hline Revista Digital de Biblioteconomia \& Ciência da Informação & $\mathrm{B} 1$ & 3 & & \\
\hline Reciis - Revista de Comunicação, Informação \& Inovação & B1 & 4 & & \\
\hline Ponto de Acesso & $\mathrm{B} 1$ & 2 & & \\
\hline Revista Brasileira de Biblioteconomia e Documentação & B1 & 2 & & \\
\hline Perspectivas em Gestão \& Conhecimento & B1 & 1 & & \\
\hline Atoz: Novas Práticas em Informação e Conhecimento & $\mathrm{B} 2$ & 2 & \multirow{4}{*}{5} & \multirow{4}{*}{$4,24 \%$} \\
\hline Acervo - Revista do Arquivo Nacional & $\mathrm{B} 2$ & 1 & & \\
\hline Cadernos Bad (Portugual) & $\mathrm{B} 2$ & 1 & & \\
\hline Comunicação \& Informação & $\mathrm{B} 2$ & 1 & & \\
\hline Datagramazero & B3 & 2 & \multirow{11}{*}{23} & \multirow{11}{*}{$19,49 \%$} \\
\hline Inclusão Social & B4 & 1 & & \\
\hline Informação \& Tecnologia & B5 & 6 & & \\
\hline Informação em Pauta & B5 & 3 & & \\
\hline Informação@ Profissões & B5 & 2 & & \\
\hline Múltiplos Olhares em Ciência da Informação & B5 & 2 & & \\
\hline Revista Analisando em Ciência da Informação & B5 & 2 & & \\
\hline Revista Conhecimento em Ação & B5 & 2 & & \\
\hline Ciência da Informação em Revista & B5 & 1 & & \\
\hline Logeion: Filosofia da Informação & B5 & 1 & & \\
\hline Prisma.Com (Portugal) & B5 & 1 & & \\
\hline Bibliotecas Universitárias: $\quad$ Pesquisas, Experiências $\mathrm{e}$ & $\mathrm{C}$ & 2 & \multirow{2}{*}{3} & \multirow{2}{*}{$2,54 \%$} \\
\hline Revista P2p \& Inovação & $\mathrm{C}$ & 1 & & \\
\hline Métodos de Información (Espanha) & - & 1 & 1 & $0,85 \%$ \\
\hline Encontro Nacional de Pesquisa em Ciência da Informação & - & 14 & 14 & $11,86 \%$ \\
\hline TOTAL & \multicolumn{3}{|c|}{118} & $100 \%$ \\
\hline
\end{tabular}

Fonte: elaboração própria, maio 2021.

Em termos de análise uma esfera essencial é situar o painel que apura quais periódicos acolhem a temática e contribuem substancialmente para realçar certo tema para a comunidade científica, assim, pautam-se algumas situações: a política padrão de seção, chamada de dossiê temático especial, chamada pública de artigo, colaborações em fluxo contínuo para a seção de tema livre, foco e escopo do periódico, a avaliação técnica realizada pelos núcleos editoriais ou processos de seleção inerentes aos grupos de pareceristas, às eventualidades e casualidades diversas. 
A temática é analisada em periódicos qualificados nos estratos A1 e A2 $(23,73 \%)$ e B1 (36,44\%) do Qualis Capes Periódicos. No periódico Informação \& Informação (A2) foram recuperados oito (8) artigos e no periódico Ciência da Informação (B1) foram recuperados nove (9) artigos. Assim, considera-se a análise a seguir desses dois títulos de periódicos ativos que favorecem o desenvolvimento da produção científica envolvendo a 'ambientude' do Big Data.

O periódico 'Ciência da Informação' é uma revista eletrônica cientifica da CI e tem por objetivo estimular e publicar artigos produzidos pelos discentes, docentes e pesquisadores em geral da área da CI e campos afins (REVISTA CIÊNCIA DA INFORMAÇÃO, 2020). Tem periodicidade semestral publicando artigos originais de investigações inéditas que enriqueçam a CI difundindo o ensino e a pesquisa. Cabe observar que os trabalhos com o tema seguem crescentes na $\mathrm{CI}$ - o número de publicações sobre o tema tem aumentado e especialmente destacam-se publicações com mais de uma autoria. A revista apresenta qualificação B1 (Qualis Quadriênio 2013-2016) e subiu no ranking Capes/Qualis.

Já o periódico 'Informação \& Informação' foi criado no ano de 1996. Nasceu com a marca de disseminar a informação científica na área da CI e difundir o diálogo intelectual entre pesquisadores, profissionais e estudantes que atuam em diferentes regiões do país e no exterior (INFORMAÇÃO \& INFORMAÇÃO, 2020). A revista atualmente recebeu na avaliação Qualis Capes (Quadriênio 2013-2016), classificação no estrato A2. Assim, com uma busca por Big Data diretamente na página web do periódico (campo conteúdo da revista) localiza-se igual quantitativo de oito (8) itens documentais.

\subsection{Painel de Pesquisadores e Produção}

Nessa multiplicidade de documentos (118 itens documentais) há história, praxia e particularidades de muitos lugares e memórias correspondentes a uma mudança de rumo da visibilidade das experiências humanas, presentes nas entrelinhas das fontes, na ação fundamental e na história das práticas historiográficas (RODRIGUES, 2020).

O Infográfico 1, expressa uma síntese por tema em torno de itens quantitativos e rede de pesquisadores envolvidos. Na amostra de 118 itens documentais composta por artigos de periódicos e anais de eventos foram levantados 308 autores. Ainda, se observa que na 
temática Big Data, alguns estudiosos se sobressaem no rol produtivo e, esse painel advém de um crescente avanço no debate do tema na pós-graduação em CI - e a Brapci recupera apenas $14(11,86 \%)$ estudos com tal temática nos anais do Enancib.

Infográfico 1 - Representação da inter-rede de colaboradores e do quantitativo de artigo conforme rede de autoria.

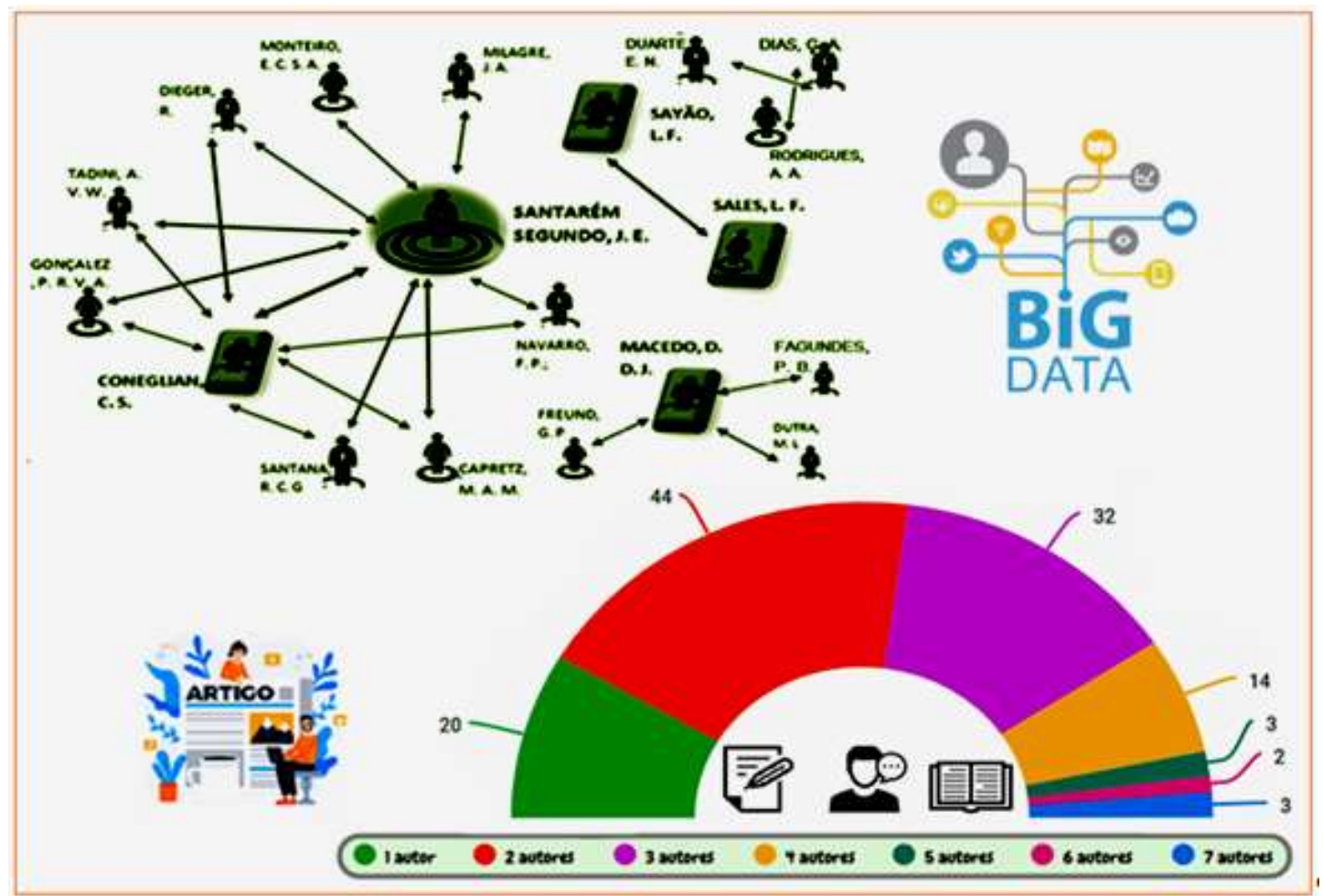

Fonte: elaboração própria, maio 2021.

Nota: produzido durante a pesquisa com base nos dados levantados na Brapci, 308 autores (2010-2019).

Cabe também destacar, no rol de dados, que foram identificados 44 autores com mais publicações de Big Data entre os itens recuperados na Brapci. Paralelamente, para confrontar as informações, a Tabela 3 apresenta o quantitativo dos 118 artigos numa distribuição da rede de colaboração - convém destacar que 44 (37,29\%) artigos foram produzidos em duplas e 32 $(27,12 \%)$ em coproduções em trio de pesquisadores. Nesse conjunto analisado foram identificados 308 autores.

Em suma, salienta-se que os olhares sobre a temática Big Data na Brapci foram analisados e ampliados pelo estudo de seis doutores, estes são: 
Tabela 3 - Perfil dos autores mais produtivos de acordo com titulação e instituição.

\begin{tabular}{|c|c|c|c|c|}
\hline AUTORES & ART & VÍNCULO & PERÍODO & OPÇÃO DE PERIÓDICO \\
\hline $\begin{array}{l}\text { SANTARÉM } \\
\text { SEGUNDO, José } \\
\text { Eduardo }\end{array}$ & 7 & $\begin{array}{l}\text { Universidade de } \\
\text { São Paulo (USP) }\end{array}$ & 2015 a 2018 & $\begin{array}{l}\text { Encontros Bibli; Informação \& } \\
\text { Tecnologia; Informação em Pauta; } \\
\text { Conhecimento em Ação }\end{array}$ \\
\hline $\begin{array}{l}\text { SAYÃO, Luís } \\
\text { Fernando }\end{array}$ & 6 & $\begin{array}{l}\text { CNEN } \\
\text { IBICT/UFRJ } \\
\text { UNIRIO }\end{array}$ & 2012 a 2019 & $\begin{array}{l}\text { Ponto de Acesso; Liinc em revista; } \\
\text { Informação \& Sociedade: Estudos; } \\
\text { Revista Conhecimento em Ação }\end{array}$ \\
\hline SALES, Luana Farias & 6 & $\begin{array}{l}\text { CNEN } \\
\text { UNIRIO }\end{array}$ & 2012 a 2019 & $\begin{array}{l}\text { Ponto de Acesso; Liinc em revista; } \\
\text { Informação \& Sociedade: Estudos }\end{array}$ \\
\hline $\begin{array}{l}\text { MACEDO, Douglas } \\
\text { Dyllon Jeronimo }\end{array}$ & 5 & $\begin{array}{l}\text { Universidade } \\
\text { Federal de Santa } \\
\text { Catarina (UFSC) }\end{array}$ & 2016 a 2019 & $\begin{array}{l}\text { Informação \& Informação; Informação } \\
\& \text { Tecnologia; RDBCI }\end{array}$ \\
\hline $\begin{array}{l}\text { CONEGLIAN, Caio } \\
\text { Saraiva }\end{array}$ & 4 & $\begin{array}{l}\text { UNESP } \\
\text { UNIVEM }\end{array}$ & 2017 a 2018 & $\begin{array}{l}\text { Em Questão; Encontros } \\
\text { Informação \& Tecnologia; } \\
\text { Conhecimento em Ação }\end{array}$ \\
\hline $\begin{array}{l}\text { FAGUNDES, Priscila } \\
\text { Basto }\end{array}$ & 4 & $\begin{array}{l}\text { Universidade } \\
\text { Federal de Santa } \\
\text { Catarina (UFSC) }\end{array}$ & 2017 a 2019 & 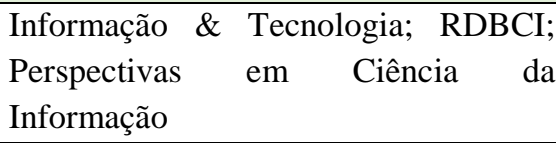 \\
\hline
\end{tabular}

Fonte: elaboração própria, maio 2021.

Nota: produzido durante a pesquisa com base nos dados da Brapci.inf e cnpq.br| 308 autores (2010-2019).

Os autores mais produtivos na área de Big Data são: José Eduardo Santarém Segundo, Professor Doutor na Universidade de São Paulo (USP) e Universidade Estadual Paulista (UNESP), com sete publicações; Luana Farias Sales Marques, pesquisadora do Instituto Brasileiro de Informação em Ciência e Tecnologia (IBICT), Departamento de Ensino e Pesquisa no Rio de Janeiro, com seis itens documentais; e, respectivamente, com seis publicações se destaca o doutor Luis Fernando Sayão do Instituto de Engenharia Nuclear, Centro de Informações Nucleares (CIN), no Rio de Janeiro.

Outras mudanças também acenam nesse palco seja no potencial criativo, seja no valor agregador dos fundos documentais do Big Data. Assim, a CI se expressa como campo dedicado às questões científicas e à prática profissional, também direcionada para os problemas da ativa comunicação do conhecimento - e como reporta Saracevic (1996), a informação é um fenômeno que deve ser estudado em conjunto com a comunicação que se situa num processo.

Para pesquisas futuras, sugere-se o aprofundamento em outros campos da ciência que possam aproveitar a temática Big Data, explorando todas as alternativas de uso possíveis. No contexto aplicado das Ciências Sociais, propõe-se maior abrangência para o assunto, abordando as vantagens competitivas e a gestão estratégica do negócio. 
Destarte, não é de se estranhar o avanço de grupos de pesquisa no Conselho Nacional de Desenvolvimento Científico e Tecnológico $(\mathrm{CNPq})$ o que referência um potencial para ampliação desse tema nas esferas do fazer - saber científico nacional, isto é representado na área de CI por oito grupos de pesquisa certificados:

- Ciência, Dados, Redes e Metrias (Scimetrics) e o grupo Gestão do Conhecimento e Prospecção em Saúde, ambos da Fundação Oswaldo Cruz (Fiocruz);

- Estudos e Práticas de Preservação Digital do Instituto Brasileiro de Informação em Ciência e Tecnologia (Ibict);

- Representação do Conhecimento, Ontologias e Linguagem da Universidade Federal de Minas Gerais (UFMG);

- Inteligência, Tecnologia e Informação - Research Group (ITI-RG) da Universidade Federal de Santa Catarina (UFSC);

- Memória Social, Tecnologia e Informação da Universidade Federal do Estado do Rio de Janeiro (UNIRIO);

- Núcleo de Estudos em Web Semântica e Análise de Dados (NEWSDA) e o Observatório do Mercado de Trabalho em Informação na Era Digital, ambos da Universidade de São Paulo (USP).

Desta forma, entende-se que a esfera da produção científica sobre Big Data carece de múltiplos debates, grandes são as provocações, pois o esforço de extrair informações de um volume alto de dados, envolve a inteligência analítica, prospectando socialmente a troca de conteúdo, o maior fluxo de comunicação, o monitoramento e controle de projetos. 


\title{
5. Considerações finais
}

\begin{abstract}
Desconfiai, do mais trivial, na aparência singela. E examine, sobretudo, o que parece habitual. Suplicamos expressamente: não aceiteis o que é de hábito como coisa natural, pois em tempo de desordem sangrenta, de confusão organizada, de arbitrariedade consciente, de humanidade desumanizada, nada deve parecer natural, nada deve parecer impossível de mudar (BRECHT, 1982, p. 32).
\end{abstract}

A expansão do Big Data acompanha o ritmo da expansão dos dados socialmente produzidos e da tecnologia gerada na ambiência da web. Destarte, com a análise bibliométrica da temática Big Data, no período de 2010 a 2019, em periódicos indexados na Base Brapci, a pesquisa pauta três painéis. $\mathrm{O}$ primeiro painel analisado se orienta ao levantamento de artigos publicados sobre Big Data em periódicos de BIB e CI, evidenciou a identificação de avanços da temática Big Data em termos de crescimento da produção cientifica no período analisado. Esse crescimento quando cotejado com a multiplicação dos grupos brasileiros de pesquisa em $\mathrm{CI}$, tratando da temática, registrados pelo $\mathrm{CNPq}$ - grosso modo, confirma o crescimento da produção científica, mas aponta também para a potencial ampliação nas esferas do fazer-saber científico nacional sobre a temática em muitos outros campos, dada a interdisciplinaridade da área e dos respectivos contextos de pesquisa (ambientes e instituições).

O segundo painel analisado dirigido à identificação de periódicos científicos com expressa representatividade na promoção dessa temática levantou um conjunto de 35 diferentes periódicos e artigos publicados em anais de diversas edições do Encontro Nacional de Pesquisa em Ciência da Informação (Enancib), evento anual promovido pela Associação Nacional de Pesquisa e Pós-graduação em Ciência da Informação (Ancib). A Base de Dados Brapci indexa aproximadamente mais de 60 títulos de periódicos, significando que o tema aparece em quase dois terços das publicações periódicas indexadas. A análise dos estratos desses periódicos em relação ao indexador Periódicos Qualis Capes (Quadriênio 2013-2016) revela que o tema circula em praticamente todos os estratos, porém situa-se privilegiadamente, com $(61,02 \%)$ nos estratos superiores (de A1 até B1), com ampla concentração no estrato B1, justamente por tratar-se também do estrato que congrega maior número de publicações periódicas.

O terceiro mural ponderado tratando da circunscrição de pesquisadores em termos de titulação, instituições de origem e as direções nos relacionamentos de coautorias caracterizaram: i) a natureza interativa que a temática provoca quanto aos modos de produção 
científica, a análise bibliométrica identificou um processo de produção colaborativa: mais da metade dos autores identificados, desenvolveram análises sobre a temática em colaboração com dois ou três autores; ii) uma perspectiva bibliográfica panorâmica sobre o Big Data, enfatizando múltiplos fenômenos informacionais correlacionados ao tema.

Considerando os aspectos teóricos e práticos da temática Big Data, no contexto da BIB e CI no Brasil, dos periódicos que fazem a circulação do tema, e os coletivos de autores que produzem essas análises teóricos-práticas identificamos o papel relevante dessas áreas no reconhecimento analítico e científico dos contextos dinâmicos, baseados em informação e das processualidades que envolvem o uso de Big Data para consumo de dados em escala. Tratando da emergência do termo na literatura pesquisada, apesar de abstrato e de pouco consenso conceitual, apresenta-se expressivo para revelar uma tendência mundial de consumo de dados em escala e para produção de informação, a partir de atividade digital com alto valor agregado, em contextos dinâmicos no ambiente web.

A análise bibliométrica realizada sobre Big Data explicita, de forma panorâmica, questões de ordem ética, legal, social, do mercado e tecnológica que estão em discussão, tratando desse fenômeno relacionado aos modos de produção e processamento de dados na contemporaneidade. A literatura analisada sinaliza para: a identificação de um contingente significativo de organizações demandando e trabalhando com volumes significativos de dados produzidos gratuitamente por usuários de redes sociais. Essas apropriações de dados implicam a produção de interpretações de ordem ética, legal e relacionadas à transparência desse processo de manipulação e uso de dados; a qualidade e volume de dados processados via Big Data; a criação de vantagem competitiva e de inovação em produtos e processos; os riscos relacionados à proteção de dados (privacidade, dados pessoais), à responsabilidade civil e aos direitos de propriedade intelectual; as mudanças no modo de análise e cruzamento de grandes volumes de informação a partir de pesquisas em escala macro analítica; o uso de Big Data como uma forte tendência da atividade digital atual para definição de padrões de geração, processamento e armazenagem de dados de usuários na web; a análise de dados (estruturados e desestruturados) objetivando tomada de decisão, desenvolvimento e aprimoramento corporativo; extração de valor em massas de dados; identificação de padrões coletivos de comportamento humano para subsidiar o processo decisório relacionado à gestão de pessoas; e expansão de campos de atuação de profissionais da informação. 
Considerando, finalmente, os traços qualitativos e históricos da literatura analisada, observa-se que a atividade digital é recente nas práticas de produção social de conhecimento. Porém, essa atividade digital, desde a década de 1940, vem sendo sinalizada junto à literatura como um estágio decorrente do processamento das descobertas advindas do grid computing. Dependendo do sistema, esse processamento em escala pode acontecer de muitas formas, seja na supercomputação distribuída sob demanda, para produção intensa de dados, ou de forma colaborativa, objetivando a alta performance no processamento de dados.

\section{Referências}

AMOROSO-FERNÁNDEZ, Yanira; COSTALES-FERRER, Dévorah. Big data: una herramienta para la administración pública. Ciencias de la Información, Cuba, v. 47, n. 3, p. 3-8, 2016. Disponível em: http://hdl.handle.net/20.500.11959/brapci/60353. Acesso em: 5 ago. 2021.

ARAÚJO JÚNIOR, Rogério Henrique de; SOUSA, Renato Tarciso Barbosa de. Estudo do ecossistema de big data para conciliação das demandas de acesso, por meio da representação e organização da informação. Ciência da Informação, Brasília, v. 45, n. 3, p. 187-198, 2016. Disponível em: http://revista.ibict.br/ciinf/article/view/4057 . Acesso em: 5 ago. 2021.

BARBOSA, Eduardo Caetano; KOBASHI, Nair Yumiko. Extroversão e descoberta: visualização de dados no auxílio a buscas e recuperação de informações. Revista Brasileira de Biblioteconomia e Documentação, São Paulo, v. 13, p. 115-120, 2017. Disponível em: http://hdl.handle.net/20.500.11959/brapci/1157. Acesso em: 5 ago. 2021.

BELONI, Aneli; BEZERRA, Arthur Coelho. Competência crítica em informação e ética em big data. In: ENCONTRO NACIONAL DE PESQUISA EM CIÊNCIA DA INFORMAÇÃO, 20, Florianópolis. Anais [...]. Florianópolis: Ancib, 2019. Disponível em: http://hdl.handle.net/20.500.11959/brapci/123813. Acesso em: 5 ago. 2021.

BRECHT, Bertolt. Antologia poética. Rio de Janeiro: Elo, 1982.

BUFREM, Leilah Santiago; SILVA, Fábio Mascarenhas e; SOBRAL, Natanael Vitor; CORREIA, Anna Elizabeth Galvão Coutinho. Produção internacional sobre ciência orientada a dados: análise dos termos data science e e-science na scopus e na web of science.

Informação \& Informação, Londrina, v. 21, n. 2, p. 40-67, 2016. DOI: 10.5433/19818920.2016v21n2p40 Acesso em: 5 ago. 2021.

CONCEIÇÃO, Joana Penêdo da. A arte da fraude no campo da informação: engenharia social, big data e a manipulação do usuário na rede. Bibliotecas Universitárias: pesquisas, experiências e perspectivas, v. 4, n. 1, 2017. Disponível em:

http://hdl.handle.net/20.500.11959/brapci/17089. Acesso em: 5 ago. 2021. 
CONEGLIAN, Caio Saraiva et al. O papel da web semântica nos processos do big data.

Encontros Bibli: Revista Eletrônica de Biblioteconomia e Ciência da Informação, Florianópolis, v. 23, n. 53, p. 137-146, set./dez., 2018. DOI: 10.5007/1518-

2924.2018v23n53p137. Disponível em:

https://periodicos.ufsc.br/index.php/eb/article/view/1518-2924.2018v23n53p137/37292.

Acesso em: 5 ago. 2021.

CONEGLIAN, Caio Saraiva; GONÇALVEZ, Paula Regina Ventura Amorim; SEGUNDO, José Eduardo Santarém. O Profissional da Informação na era do Big Data. Encontros Bibli: Revista Eletrônica de Biblioteconomia e Ciência da Informação, Florianópolis, v. 22, n. 50, p. 128-143, set./dez. 2017. DOI: 10.5007/1518-2924.2017v22n50p128 Acesso em: 18 ago. 2021.

COSTA, Maíra Murrieta; CUNHA, Murilo Bastos. A literatura internacional sobre e-science nas bases de dados lisa e lista. Encontros Bibli: Revista Eletrônica de Biblioteconomia e Ciência da Informação, Florianópolis, v. 20, n. 44, p. 127-144, 2015. DOI: 10.5007/15182924.2015v20n44p127 Acesso em: 5 ago. 2021.

FAGUNDES, Priscila Basto; MACEDO, Douglas Dyllon Jeronimo; FREUND, Gislaine Parra. A produção científica sobre qualidade de dados em big data: um estudo na base de dados web of science. Revista Digital de Biblioteconomia \& Ciência da Informação, Campinas, v. 16, n. 1, p. 194-210, 2018. DOI: 10.20396/rdbci.v16i1.8650412. Acesso em: 5 ago. 2021.

FAGUNDES, Priscila Basto; MACEDO, Douglas Dyllon Jeronimo; DUTRA, Moisés Lima. Uma análise das relações entre a qualidade da informação e big data. In: ENCONTRO NACIONAL DE PESQUISA EM CIÊNCIA DA INFORMAÇÃO, 18., 2017, Marília, SP. Anais [...]. Marília: Ancib, 2017. Disponível em: https://brapci.inf.br/index.php/res/v/104236. Acesso em: Acesso em: 24 jul. 2021.

FRANCISCO, Quevellin Alves dos Santos; SILVA, Thais Oliveira da; MARTINEZ, Maria Regina. Recursos humanos em saúde: do processo intuitivo ao people analytics. Revista Eletrônica de Comunicação, Informação e Inovação em Saúde, Rio de Janeiro, v. 13, n. 1, 2019. DOI: 10.29397/reciis.v13i1.1370. Acesso em: 5 ago. 2021.

FREUND, Gislaine Parra; FAGUNDES, Priscila Basto; MACEDO, Douglas Dyllon Jeronimo; DUTRA, Moisés Lima. Mecanismos tecnológicos de segurança da informação no tratamento da veracidade dos dados em ambientes Big Data. Perspectivas em Ciência da Informação, Belo Horizonte, v. 24, n. 2, p. 124-142, jul. 2019. Disponível em: http://portaldeperiodicos.eci.ufmg.br/index.php/pci/article/view/3348. Acesso em: 5 ago. 2021.

HAN, Byung-Chul. Psicopolítica: o neoliberalismo e as novas técnicas de poder. Tradução de Maurício Liesen. Belo Horizonte: Âyiné, 2018.

INFORMAÇÃO \& INFORMAÇÃO. Revista Informação \& informação, Londrina: UEL, 2020. Disponível em: 
Big Data na Base de Dados Referencial de Artigos de Periódicos em Ciência da Informação

(Brapci): um enfoque situacional

http://www.uel.br/revistas/uel/index.php/informacao/about/editorialPolicies\#focusAndScope. Acesso em: 8 jun. 2021.

LINS, Greyciane Souza. A tecnologia e a cultura de informação como espaço de pesquisa para a ciência. Biblios, Lima, n. 61, p. 85-92, 2015. DOI: 10.5195/biblios.2015.261 Disponível em: http://biblios.pitt.edu/ojs/index.php/biblios/article/view/261. Acesso em: 5 ago. 2021.

LOTT, Yuri Monnerat; CIANCONI, Regina de Barros. Vigilância e privacidade, no contexto do big data e dados pessoais: análise da produção da ciência da informação no brasil.

Perspectivas em Ciência da Informação, Belo Horizonte, v. 23, n. 4, p. 117-132, 2018. Disponível em: http://hdl.handle.net/20.500.11959/brapci/108454. Acesso em: 5 ago. 2021.

MARTÍNEZ-MARTÍNE, Silvia; LARA-NAVARRA, Pablo. El big data transforma la interpretación de los medios sociales. Profesional de la Información, Leão, v. 23, n. 6, p. 575-581, 2014. DOI: 10.3145/epi.2014.nov.03. Disponível em: https://revista.profesionaldelainformacion.com/index.php/EPI/article/view/epi.2014.nov.03. Acesso em: 5 ago. 2021.

OHL, Rodolfo. Big data: como analisar informações com qualidade. Canaltech, São Bernardo do Campo, 7 mar. 2014. Disponível em: https://canaltech.com.br/big-data/Big-Datacomo-analisar-informacoes-com-qualidade/. Acesso em 16 jul. 2021.

OUSSOUS, Ahmed; BENJELLOUN, Fatima-Zahra; LAHCEN, Ayoub Ait; BELFKIH, Samir. Big data technologies: A survey. JKSUCI: Journal of King Saud University - Computer and Information Sciences: Elsevier, Riyadh, v. 30, n. 4, p. 431-448, Oct. 2018. Disponível em: https://www.sciencedirect.com/science/article/pii/S1319157817300034. Acesso em 19 jul. 2021.

PEIXOTO, Leticia de Castro; BARBOSA, Ricardo Rodrigues. Potencial de inovação através do big data analytics: panorama das últimas pesquisas. In: ENCONTRO NACIONAL DE PESQUISA EM CIÊNCIA DA INFORMAÇÃO, Marília, 2017. Anais [...]. Marília: Ancib, 2017. Disponível em: https://www.brapci.inf.br/index.php/res/v/104543. Acesso em 8 jul. 2021.

RAMOS, Atos. Infraestrutura big data com opensource. Rio de janeiro: Ciência Moderna, 2015.

RAUTENBERG, Sandro; CARMO, Paulo Ricardo Viviurka do. Big data e ciência de dados: complementariedade conceitual no processo de tomada de decisão. Brazilian Journal of Information Science: research trends, Marília, v. 13, n. 1, p. 56-67, 2019. DOI: 10.36311/1981-1640.2019.v13n1.06.p56. Disponível em: https://revistas.marilia.unesp.br/index.php/bjis/article/view/8315. Acesso em: 5 ago. 2021.

REIS, Luiz Claudio Rezende; Sá, Maria Irene da Fonseca e. Big data: um novo campo de atuação para bibliotecários. Prisma.com (Portugual), Porto, n. 41, p. 231-250, 2020. Disponível em: http://hdl.handle.net/20.500.11959/brapci/135715. Acesso em: 5 ago. 2021. 
REVISTA CIÊNCIA DA INFORMAÇÃO. Revista ciência da informação, Brasília, 2020. Disponível em: http://revista.ibict.br/ciinf/about. Acesso em: 8 jul. 2021.

RODRIGUES, Aldair. Humanidades digitais e diáspora africana: questões éticas e metodológicas na elaboração de uma base de dados sobre a população escravizada de mariana (século xviii). Rio de Janeiro. Estudos Históricos, v. 33, n. 69, p. 64-87, 2020. Disponível em: https://doi.org/10.1590/s2178-14942020000100005. Acesso em: 10 jul.2021.

RODRIGUES, Adriana Alves; DUARTE, Emeide Nóbrega; DIAS, Guilherme Ataíde. Desafios da gestão de dados na era do Big Data: perspectivas profissionais. Informação \& Tecnologia, João Pessoa, v. 4, n. 2, p. 63-79, 2017. Disponível em: http://hdl.handle.net/20.500.11959/brapci/101621. Acesso em: 5 ago. 2021

SANGEETHA, J.; PRAKASH, V. Sinthu Janita. A survey on big data mining techniques. IJCSIS: International Journal of Computer Science and Information Security, Pittsburgh, v. 15, n. 1, p. 482, 2017. Disponível em: https://www.academia.edu/31932071/A_Survey_on_Big_Data_Mining_Techniques. Acesso em: 15 ago. 2021.

SANTOS, Gildenir Carolino; FERREIRA, Danielle Thiago. Editorial: Uso, estudo e a cultura dos métodos bibliométricos. RDBCI: Revista Digital de Biblioteconomia e Ciência da Informação, Campinas, v. 15, n. 1, p. 1-6, 2017. DOI: 10.20396/rdbci.v15i1.8648213. Disponível em: https://periodicos.sbu.unicamp.br/ojs/index.php/rdbci/article/view/8648213. Acesso em: 5 ago. 2021.

SANTOS-D’AMORIM, Karen Isabelle dos; CRUZ, Rúbia Wanessa dos Reis; SILVA, Marcela Lino da; CORREIA, Anna Elizabeth Galvão Coutinho. Dos dados ao conhecimento: tendências da produção científica sobre Big Data na Ciência da Informação no Brasil. Encontros Bibli: Revista Eletrônica de Biblioteconomia e Ciência da Informação, Florianopólis, v. 25, p. 1-23, 2020. DOI: https://doi.org/10.5007/1518-2924.2020.e70527 Acesso em: 5 ago. 2021.

SARACEVIC, Tefko. Ciência da informação: origem, evolução e relações. Perspectivas em Ciência da Informação, Belo Horizonte, v.1, n.1, 1996. Disponível em: http://portaldeperiodicos.eci.ufmg.br/index.php/pci/article/view/235. Acesso em: 10 jul.2021.

SILVA, Luiz Carlos da; MIGUEL, Marcelo Calderari; COSTA, Rosa da Penha Ferreira da. Patrimônio documental no enfoque da literatura científica: um estudo bibliométrico na base de periódicos em ciência da informação. Brazilian Journal of Information Science: research trends, Marília, v. 15, p. e02104, 2021. DOI: 10.36311/1981-1640.2021.v15.e02104. Disponível em: https://revistas.marilia.unesp.br/index.php/bjis/article/view/10170. Acesso em: 19 ago. 2021.

SILVA, Márcia Regina; HAYASHI, Carlos Roberto Massao; HAYASHI, Maria Cristina Piumbato Innocentini. Análise bibliométrica e cientométrica: desafios para especialistas que atuam no campo. InCID: Revista de Ciência da Informação e Documentação, Ribeirão Preto, v. 2, n. 1, p. 110-129, 2011. DOI: 10.11606/issn.2178-2075.v2i1p110-129. Disponível em: https://www.revistas.usp.br/incid/article/view/42337. Acesso em: 5 ago. 2021. 
SOUZA, Renato Rocha; ALMEIDA, Mauricio Barcellos; PORTO, Renata Maria Abrantes Baracho. Ciência da informação em transformação: big data, nuvens, redes sociais e web semântica. Ciência da Informação, Brasília, v. 42, n. 2, 2013. DOI: 10.18225/ci.inf..v42i2.1379. Disponível em: https://www.brapci.inf.br/index.php/res/v/19189. Acesso em: 05 ago. 2021.

SZINVELSKI, Mártin Marks; ARCENO, Taynara Silva; FRANCISCO, Lucas Baratieri. Perspectivas jurídicas da relação entre big data e proteção de dados. Perspectivas em Ciência da Informação, Belo Horizonte, v. 24, n. 4, p. 132-144, 2019. Disponível em: http://hdl.handle.net/20.500.11959/brapci/126853. Acesso em: 5 ago. 2021.

VANZ, Samile Andréa de Souza; SANTIN, Dirce Maria; PAVÃO, Caterina Marta Groposo. A bibliometria e as novas atribuições profissionais nas bibliotecas universitárias. InCID:

Revista de Ciência da Informação e Documentação, Ribeirão Preto, v. 9, n. 1, p. 4-24, 2018. DOI: 10.11606/issn.2178-2075.v9i1p4-24. Disponível em:

https://www.revistas.usp.br/incid/article/view/137741. Acesso em: 5 ago. 2021.

Artigo submetido em: 12 nov. 2020

Artigo aceito em: 27 ago. 2021 